\title{
The Yale Outcome Study: Outcomes for Graduates with and without Dyslexia
}

\author{
Sally E. Shaywitz ${ }^{1}$ John M. Holahan ${ }^{1} \cdot$ Blair Kenney $^{2} \cdot$ Bennett A. Shaywitz $^{1}$
}

Received: 27 September 2020 / Revised: 27 September 2020 / Accepted: 4 October 2020 / Published online: 13 October 2020

(C) The Author(s) 2020

\begin{abstract}
Dyslexia is defined in recent federal legislation as an unexpected difficulty in reading for an individual who has the intelligence to be a much better reader. Despite its high prevalence (20\%), there have been few studies of the experience and outcome of dyslexic students at selective 4-year colleges. We examined academic and social experiences in college and outcome in the workplace 5 or more years after graduation in Yale graduates with dyslexia compared with a matched group of Yale graduates who were typical readers. Dyslexic college graduates did not differ from typical graduates in college and the workplace. Parents of dyslexic children often ask about their child's future. These findings should reassure those professionals (including pediatric neuropsychologists, school psychologists and pediatricians) that dyslexic students can be successful in school and go on to succeed and thrive at selective colleges.
\end{abstract}

Keywords Dyslexia $\cdot$ Learning disability $\cdot$ Outcome $\cdot$ College $\cdot$ Workplace

\section{Abbreviations \\ DR Dyslexic readers \\ TR Typical readers \\ SAT Scholastic Aptitude Test \\ ACT American College Test \\ LD Learning disability}

Dyslexia is the most common neurobehavioral disorder in children and young adults, affecting $20 \%$ of the population (Ferrer et al. 2015). It was first described in the late nineteenth century (Morgan 1896) as an unexpected difficulty in reading. Now, a century later, in the most up-to-date definition, codified in Public Law No: 115-391 (First Step Act 2018), dyslexia continues to be defined as "an unexpected difficulty in reading for an individual who has the intelligence to be a much better reader, most commonly caused by a difficulty in the phonological processing (the appreciation of the individual sounds of spoken language), which affects the ability of an

Sally E. Shaywitz

sally.shaywitz@yale.edu

1 From the Department of Pediatrics, Section of Pediatric Neurology, Yale University School of Medicine, 129 York St., Suite 1P, New Haven, CT 06511, USA

2 Great Lakes Counseling Center, Addison, TX, USA individual to speak, read, and spell," a definition empirically supported (Ferrer et al. 2010).

Pediatric neuropsychologists, school psychologists, pediatricians, and other professionals are often consulted by parents concerned about their dyslexic children not only in the kindergarten to 12 th grade years but worried about their futures after high school, for example, college admissions and career possibilities. Much of this worry can be traced back to the well-founded knowledge that dyslexic readers typically are not automatic readers, but rather are slow readers. Unfortunately, this has led to the belief that dyslexics are slow thinkers and not very bright. Common concerns shared by many including college and university admissions officers tasked with admitting dyslexic students include the following: How they will do? Can dyslexic students manage the work load? Will they be successful following graduation? Despite its high prevalence there have been few studies of the experience and outcome of dyslexic students at selective 4-year colleges. Furthermore, previous studies of performance of dyslexic students in college and their subsequent experience in the workplace following graduation have confounded dyslexia with the broad, non-specific category of learning disabilities. This study was designed to address these previous limitations.

We hypothesized that dyslexic college students admitted to a selective college would do well academically and socially and would be successful following graduation. 


\section{Method}

\section{Overall Study Design}

Two groups of Yale graduates, dyslexic readers (DR) and typical readers (TR), were recruited, each at least 5 years after graduation. Participants responded to questions about both their Yale experience and also their work and life experiences since graduation. Subjects (equally divided between DR and TR) completed a 150-question survey asking about their academic experience at Yale, level of self-esteem at Yale, employment after college, work ethic, and learning style. The study was approved by the Institutional Review Board at Yale University and was conducted in accordance with the ethical principles that have their origin in the Declaration of Helsinki and are consistent with good clinical practices and applicable laws and regulations.

\section{Participants}

Dyslexic reader (DR) participants were identified from the population of Yale University graduates who completed their bachelor's degree and graduated 5 years or more before the time of data collection. Fifty-one individuals were identified who had been diagnosed as dyslexic and had received academic accommodations at Yale as confirmed by their records at the Resource Office on Disabilities. The Yale Center for Dyslexia and Creativity had evaluated these individuals most commonly for their slow reading and need for the academic accommodation of extended time. The final DR sample consisted of 43 participants, 32/43 (74\%) male.

Individuals for the typical reader (TR) sample were selected in two stages from records obtained from the Alumni Office at Yale University. In the first stage, 100 TR alumni were selected randomly and matched by gender, graduation year, and distributional group of majors to the DR group. TR candidates were selected in a 2:1 ratio to the DR sample because we anticipated a lower response rate from that group. Because Yale offers over 70 majors, individuals were grouped into one of the four distributional groups of majors: languages (including English), humanities, social sciences, and natural sciences and mathematics. Of the 100 TR candidates, 70 were contacted successfully. The final TR sample consisted of 43 participants, 24/43 (56\%) male. The gender disparity between the groups approached statistical significance (Fisher's Exact $p=.08)$. The recruitment rates were $43 / 51(84 \%)$ for the DR group and 43/70 (61\%) for the TR group.

Participants described their current or most recent employment, which was classified using the Standard Occupational Classification from the Bureau of Labor Statistics. Employment characteristics of the DR and TR groups are presented in Table 1 . The most frequent categories of employment among the DR participants were business and finance
Table 1 Employment classifications of the dyslexia and typical reader groups

\begin{tabular}{|c|c|c|c|c|c|c|}
\hline \multirow[b]{2}{*}{ Employment } & \multicolumn{2}{|c|}{ DR } & \multicolumn{2}{|c|}{$\mathrm{TR}$} & \multicolumn{2}{|c|}{ Total } \\
\hline & $\mathrm{n}$ & $\%$ & $\mathrm{n}$ & $\%$ & $\mathrm{n}$ & $\%$ \\
\hline Arts/entertainment & 3 & 7.0 & 6 & 14.0 & 9 & 10.5 \\
\hline Business and finance & 9 & 20.9 & 6 & 14.0 & 15 & 17.4 \\
\hline Computers and mathematics & 2 & 4.7 & 4 & 9.3 & 6 & 7.0 \\
\hline Education & 4 & 9.3 & 7 & 16.3 & 11 & 12.8 \\
\hline Government & 4 & 9.3 & 1 & 2.3 & 5 & 5.8 \\
\hline Healthcare & 4 & 9.3 & 4 & 9.3 & 8 & 9.3 \\
\hline Legal occupations & 4 & 9.3 & 5 & 11.6 & 9 & 10.5 \\
\hline Life, physical, and social sciences & 3 & 7.0 & 2 & 4.7 & 5 & 5.8 \\
\hline Management & 8 & 18.6 & 7 & 16.3 & 15 & 17.4 \\
\hline Missing & 2 & 4.7 & 1 & 2.3 & 3 & 3.5 \\
\hline Total & 43 & 100 & 43 & 100 & 86 & 100 \\
\hline
\end{tabular}

(20.9\%) and management (18.6\%), whereas the most frequent areas of employment among the TR participants were education $(16.3 \%)$ and management (16.3\%). Most participants in both groups were currently employed at full-time jobs, defined as work for pay or profit that totaled $35 \mathrm{~h}$ or more per week (DR, 60\%; TR, 49\%). Private employers (DR, 53\%; TR, $67 \%$ ) employed most participants. Estimations of their annual household income bracket revealed DR median $\$ 75,000-\$ 99,999$ and TR median $\$ 100,000-\$ 150,000$; the reader groups did not differ significantly (Mann-Whitney$U=945.5, p=.222, n=81)$.T.

\section{Measures}

The main survey, completed by both groups, was designed to gather data regarding participants' retrospective selfassessments of their overall academic experiences in college and their current assessment of their adult lives. Separate sections, unique to each group, included additional questions for the DR group pertaining to learning issues specific to readers with dyslexia and additional questions pertaining to learning history for the TR group so that individuals at risk for dyslexia who did not disclose their status to the Resource Office on Disabilities could be identified and excluded from the TR group.

Domains assessed regarding experiences in college included retrospective self-assessment of readiness for the academic demands of college and their effects on stress, study habits, social life, extra-curricular activities, and the need for extra time on assignments and its negative consequences. Domains assessed regarding current experiences included employment, life and relationship satisfaction, confidence in 
employment goals, work perseverance, and work stress and self-esteem.

Most items on the survey were constructed in a 5-point Likert scale format. Scales constructed from the Likert scale items were based on content validity and assessed for empirical reliability. The scales reported here ranged from 2 to 12 items with $\alpha$ reliability coefficients ranging from $\alpha=.63-.87$ and are individually reported in Tables 2 and 4. Categorical dichotomous items were also included in the survey. We report categorical outcomes for several college experience variables and current health indicators. Finally, the survey included open-ended questions that enabled the respondent to add relevant descriptive or contextual information to elaborate on their chosen response to the survey questions. The items and scales were largely adapted from the Yale Adult Survey of the Connecticut Longitudinal Study which was designed to identify the long-term adult outcomes of childhood reading disability. Many of the items from the Self-Assessment Scale were adapted from the Rosenberg Self-Esteem Scale (Rosenberg, 1965).

\section{Analysis}

This study is a two-group comparative study. Likert scale items within scale were averaged to maintain raw score means within the range of $1-5$ points. Individual Likert scale items and Likert scales were analyzed in a two-way ANOVA Group x Gender design.

\section{Results}

\section{College Experiences}

The only statistically significant difference in the academic experience of the dyslexic and non-dyslexic alums was "time needed to complete school work," which was reported by more dyslexic respondents. There were no significant differences in "difficulty and enjoyment of classes," "selfperceived confidence, motivation, and intelligence," or in "academic stress." Responses to survey questions about participation in college life were reassuring; the dyslexic group indicated that they did not spend any less time in extracurricular activities. Compared with their non-dyslexic fellow Yale graduates, the dyslexic alums showed a trend toward higher overall self-esteem when they were in college.

More specific results of the retrospective college experiences are presented in Table 2. As noted, the motivation, confidence, and intelligence in college yielded no significant differences for reader group, gender, or their interaction. Ratings of the Academic Stress in college did not differ for the group main effect, but there was an observed trend $F(1,81)=3.65$, $p<.10$ for gender main effect with females rating their academic

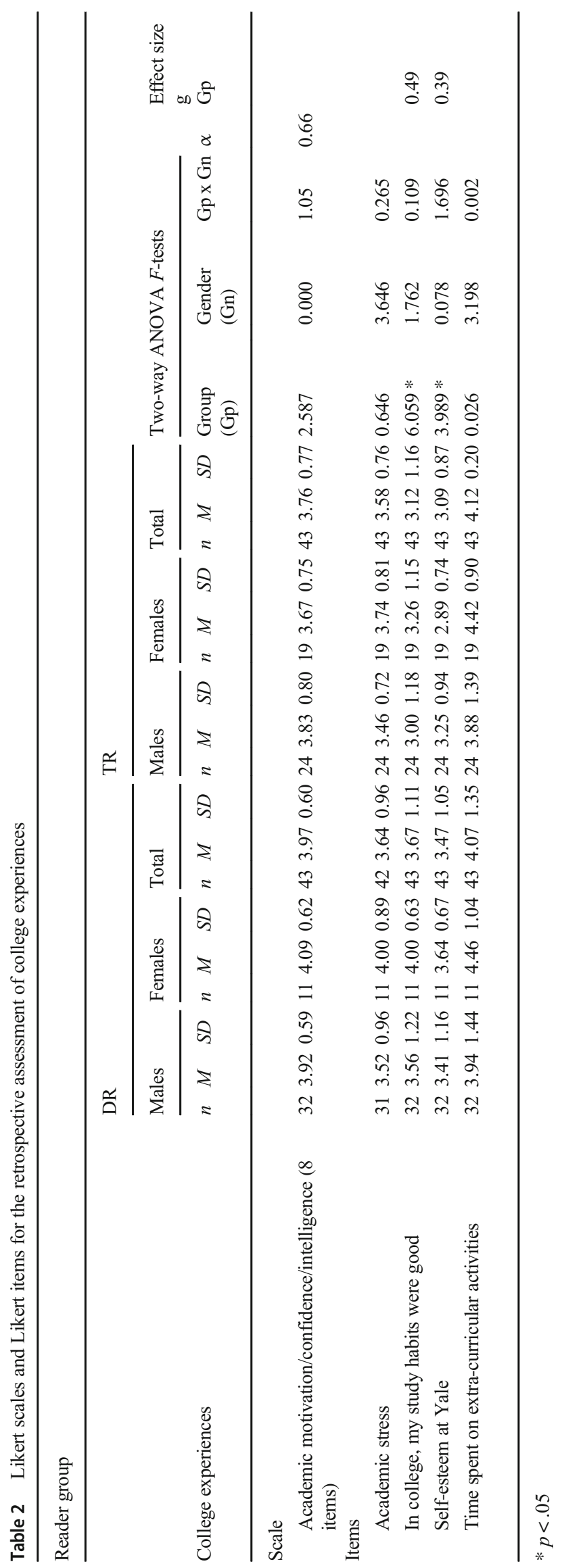


stress higher than males. The group $\mathrm{x}$ gender interaction was not statistically significant for this, and all other dependent variables analyzed in the study. One item, "In college, my study habits were good," demonstrated a significant difference between DR and TR and favored DR, $F(1,82)=6.06, p=0.016$, Hedges' $g=$ 0.49 . Neither the main effect for gender nor the two-way interaction was statistically significant.

Self-esteem differed significantly between the reader groups $F(1,82)=3.99, p=0.049$, Hedges' $g=0.39$, with the DR group having higher ratings (better self-esteem). The reader groups did not differ on time spent on extra-curricular activities. There was an observed trend indicating that females spent more time on extra-curricular activities than did males $F(1,82)=3.20, p=0.077$.

Results for the retrospective college experiences related to the need for extra time and its consequences are presented in Table 3. Just over 50\% $(n=22)$ of the DR participants felt the need for more time to complete their work, whereas $30 \%(n=$ 13) of the TR group felt the need for more time with the difference between the groups nearly reaching statistical significance $(p=0.078)$. The DR group identified one or more negative effects on their behavior (e.g., less sleep, participation in fewer activities) significantly more often than their TR colleagues did $(p=0.046)$. There was an observed trend $(p=0.067)$ indicating that more DR group participants experienced one or more negative emotional consequences of needing more time (anger, frustration, depression) than their TR colleagues did.

No significant differences between the DR and TR groups were found for ratings of the difficulty or enjoyment of their classes. Similar percentages (67-74\%) from the DR and TR groups rated their classes as being at least moderately difficult and the same majority (72\%) from each group reported that they frequently enjoyed their classes.

\section{Post-College Experiences}

The same positive pattern extended into the post-graduate years in responses to questions about their employment and their work ethic/perseverance. Overall, there were no statistically significant differences found between the two groups in terms of income, future outlook, relationship satisfaction, life satisfaction, or in confidence in goal achievement.

Details of current adult experience are presented in Table 4. No significant main or interaction effects were found for two components of satisfaction: Employment and Life/Relationship. Observed trends for the Life Satisfaction scale were found for Group $F(1,82)=3.88, p=0.052$, with the DR group more satisfied. An effect for gender was also observed $F(1,82)=3.88, p=0.058$, with females more satisfied.

No significant differences were found between the reader groups for their confidence in employment goals and for future outlook. The DR group had a significantly higher selfassessment of creativity than the TR group did $F(1,82)=$ 5.781, $p=0.018, \mathrm{~g}=.55$.

The main effect for group was not significant on the SelfAssessment Scale assessing aspects of global self-esteem; an observed trend indicated that females assessed themselves higher than males $F(1,82)=, p=0.097$. The main effect for Group on the Work Perseverance scale was significant $F(1,82)=9.412, p=0.003, \mathrm{~g}=.76$ with the DR group having higher ratings.

No difference was found between the DR and TR on work stress assessed for both graduate school and current work environment. A significant main effect for gender indicated that males experienced higher levels of work stress than females $F(1,82)=4.913, p=0.029, \mathrm{~g}=.55$. As hypothesized, no significant differences between DR and TR were found for self-esteem (post-college).

Results for indicators of physical and mental health are presented in Table 5. Rates for the physical health indicators did not differ between the groups, and the rates for the mental health indicators also did not differ between the groups, although the use of medication to help concentration for the DR group (19\%) was more than double that of the TR group (7\%). Among the dyslexic participants, $44 \%$ reported that they would change the fact that they were dyslexic if they could, while $56 \%$ reported that they would not.
Table 3 Retrospective assessment of college experiences - categorical items

\begin{tabular}{|c|c|c|c|c|c|c|}
\hline \multirow[b]{2}{*}{ Item } & \multicolumn{2}{|c|}{ DR Yes } & \multicolumn{2}{|c|}{ TR Yes } & & \multirow{2}{*}{$\begin{array}{l}\begin{array}{l}\text { Fisher's } \\
\text { Exact }\end{array} \\
\mathrm{p}\end{array}$} \\
\hline & $\mathrm{n}$ & $\%$ & $\mathrm{n}$ & $\%$ & & \\
\hline $\begin{array}{l}\text { At Yale, did you feel that you needed more time to complete } \\
\text { your assignments than many of your friends needed }\end{array}$ & 22 & 51.3 & 13 & 30.2 & & 0.078 \\
\hline $\begin{array}{l}\text { One or more negative effects of needing more time on work } \\
\text { (sleep less, fewer activities) }\end{array}$ & 22 & 51.3 & 12 & 27.9 & * & 0.046 \\
\hline $\begin{array}{l}\text { One or more Negative feelings toward needing more time } \\
\text { (anger, depression) }\end{array}$ & 19 & 44.2 & 10 & 23.3 & & 0.067 \\
\hline Yale classes were difficult for you. & 32 & 74.4 & 29 & 67.4 & & $>.80$ \\
\hline You enjoyed your classes at Yale & 31 & 72.1 & 31 & 72.1 & & $>.80$ \\
\hline
\end{tabular}




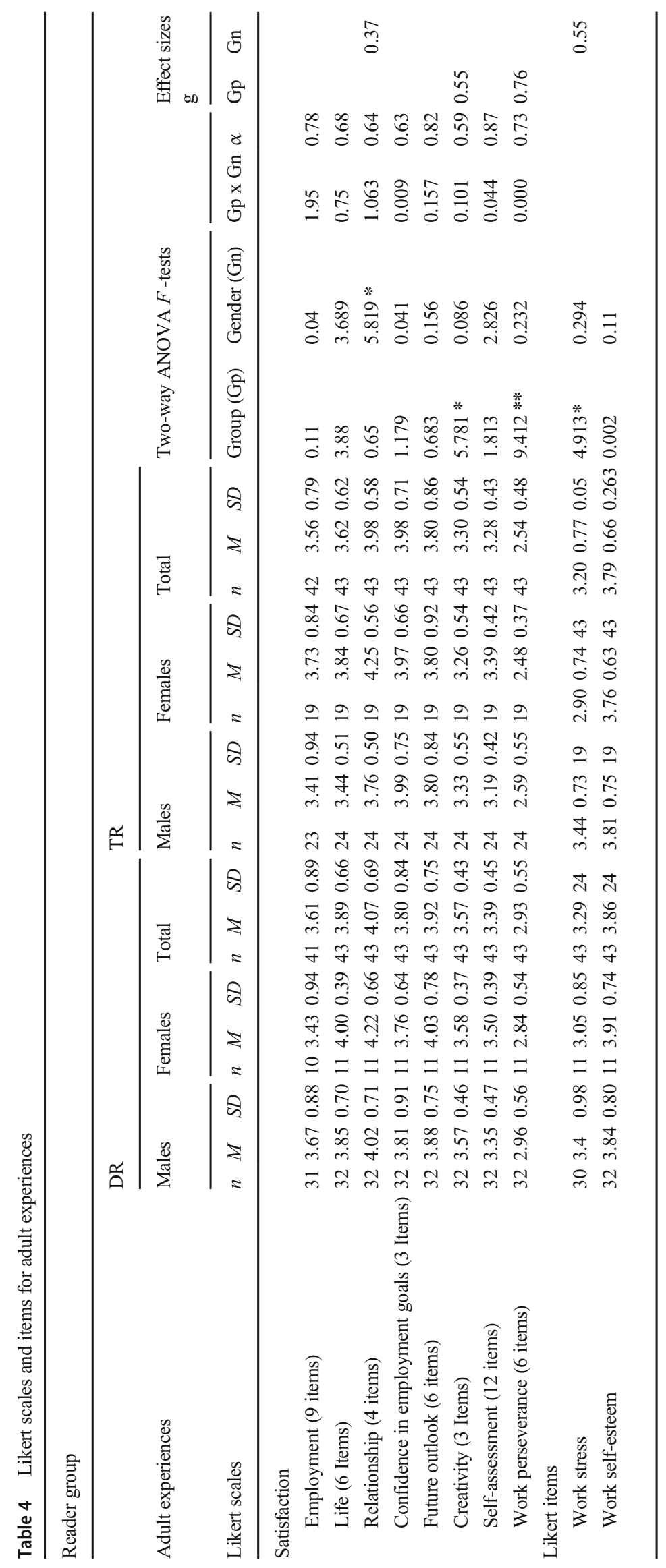


Table 5 Categorical physical and mental health indicators

\begin{tabular}{|c|c|c|c|c|c|}
\hline \multirow{2}{*}{$\begin{array}{l}\text { Health indicator } \\
\text { Physical }\end{array}$} & \multicolumn{2}{|c|}{ DR Yes } & \multicolumn{2}{|c|}{ TR Yes } & \multirow{2}{*}{$\begin{array}{l}\text { Fisher's } \\
\text { Exact } \\
p\end{array}$} \\
\hline & $n$ & $\%$ & $n$ & $\%$ & \\
\hline $\begin{array}{l}\text { Do you have any health problems, impairment, or disability now that } \\
\text { keeps you from participating fully in work, school, homework, or } \\
\text { other activities? }\end{array}$ & 8 & 18.6 & 7 & 16 & $>.80$ \\
\hline $\begin{array}{l}\text { Do you have a chronic (over } 6 \text { months) health problem or disability } \\
\text { (such as diabetes or asthma)? }\end{array}$ & 13 & 30.2 & 11 & 26 & $>.80$ \\
\hline $\begin{array}{l}\text { Since age 19, have you ever had a serious illness (like cancer or } \\
\text { diabetes)? }\end{array}$ & 5 & 11.6 & 5 & 12 & $>.80$ \\
\hline \multicolumn{6}{|l|}{ Mental } \\
\hline $\begin{array}{l}\text { Have you ever received any professional counseling, treatment or } \\
\text { therapy? }\end{array}$ & 23 & 53.5 & 25 & 58 & $>.80$ \\
\hline $\begin{array}{l}\text { Have you taken any medication prescribed by a doctor for } \\
\text { depression? }\end{array}$ & 12 & 27.9 & 12 & 28 & $>.80$ \\
\hline $\begin{array}{l}\text { Have you taken any medication prescribed by a doctor to help you } \\
\text { concentrate? }\end{array}$ & 8 & 18.6 & 3 & 7.0 & 0.20 \\
\hline $\begin{array}{l}\text { Have you taken any medication prescribed by a doctor to help you } \\
\text { reduce anxiety? }\end{array}$ & 10 & 23.3 & 13 & 30 & 0.63 \\
\hline Have you been in the hospital for psychological or mental health reasons? & 1 & 2.3 & 0 & 0 & $>.80$ \\
\hline
\end{tabular}

Reading some of the statements of these Yale graduates helps to shed light on how these young men and women were able to be so successful. For example, there was a recurring focus on their strengths:

"Dyslexia taught me how to take advantage of what I am
good at, and learn to manage my weaknesses."
Many came to view dyslexia as responsible for their
success:
"In my work, it is very useful to fully grasp and under-
stand the material I am reading, so in many ways, my
slow reading may help my job performance."
Perseverance was noted by almost all the dyslexic re-
spondents, for example:
"I don't give up easily." "Dyslexia has helped me in the
long run because I've always worked harder than my
peers."
A different way of thinking was expressed as well:
"I find I look at the bigger picture and can solve
problems."

\section{Discussion}

These results provide valuable new insights into the complex experience of dyslexic students at a selective college and align with the latest scientific understanding of dyslexia. For example, dyslexia is an unexpected difficulty - in typical readers IQ and reading levels are dynamically linked; that is, if a person has a high level of intelligence, he will generally be a good reader. In contrast, in dyslexic individuals, IQ and reading diverge; that is, dyslexics often have a high IQ and read at a much lower level (Ferrer et al. 2010). These findings indicate that a person's intelligence and future should not be judged by their poor or slow reading.

We find better study habits and high self-esteem together with high levels of work perseverance and resourcefulness perhaps offsetting the negative effects of needing more time to complete work. These findings of undergraduate experiences for both DR and TR were generally consistent with our expectations though we were surprised that DR and TR reported comparable levels of academic stress in college, in graduate school, and at work as adults.

Our findings indicate that DR were able to achieve high levels of job satisfaction comparable to that of TR and are consistent with studies by Madaus and colleagues for the more general LD (Madaus et al. 2003, 2008). We suspect that DR devise successful strategies for managing their weaknesses and to find jobs that capitalized on their strengths, an explanation supported by responses such as: "Especially when I was in sales, I had to be very meticulous and be very involved in my work because I had dyslexia. I also learned social skills to cope with my dyslexia (such as making friends, asking for help, and networking)." Another respondent spoke about the professional advantages of having dyslexia: "Because I read slowly, I tend to focus more on what I am reading, and I think that helps me absorb the material better than some."

Accepting and positively reframing one's dyslexia appears to be a key to success and adjustment. By ascribing a new and positive meaning to their dyslexia, individuals can change their expectations of themselves and develop a plan of action to achieve their goals (Gerber et al. 1996).

In this study, a majority of graduates with dyslexia (56\%) responded that they would not change the fact that they had dyslexia. This finding suggests that many of our participants 
perceived that they could successfully manage their weaknesses and cultivate their strengths, including those that resulted from having dyslexia. Many respondents spoke about being more determined or hardworking because of their dyslexia. One participant explained: "Perhaps [my] dyslexia has made me a harder worker and has taught me to keep innovating and coming up with more effective methods to work." Previous studies on employment satisfaction of college graduates with a learning disability have found perceptions of selfefficacy to be the greatest contributor to job satisfaction (Madaus et al. 2003, 2008). It is likely that our sample of alumni with dyslexia developed effective coping strategies, which increased their perceptions of self-efficacy, which in turn contributed to their job satisfaction.

We also found no significant difference between the graduates with dyslexia and typical graduates on a self-assessment of global self-esteem, corroborating findings that college students with learning disabilities who received university support services did not differ from their peers in global selfconcept (Cosden and McNamara 1997; Lewandowski and Arcangelo 1994). Our findings now extend to adults with dyslexia following college graduation, even when many support services come to an end.

The open-ended responses of many of the dyslexic participants in this study indicate that they saw their dyslexia as an encapsulated disability. These responses reflect and are consistent with our sea of strengths model of dyslexia (Shaywitz and Shaywitz 2020) which posits that dyslexia can be conceptualized as a circumscribed difficulty in decoding (slow reading as the person matures) surrounded by a sea of strengths in higher level cognitive functions such as concept formation, critical thinking, reasoning and problem solving. One respondent explained, "In my own experience with my disability, [it is] very localized in terms of what it affects." A minority (44\%) of respondents with dyslexia stated that they would prefer not to be dyslexic, providing reasons such as difficulties with learning a foreign language, recalling names and numbers, and reading quickly, findings which are consonant with results of our recent report (Herrera-Araujo et al. 2017) showing that dyslexic adults were willing to pay much more than typical readers to read aloud better.

We were surprised to find that the two groups of graduates did not differ on the measure of work stress. This finding suggests that having dyslexia has less than predicted impact on the generally assumed work-related stress in college, graduate school, or post-college employment (Adelman and Vogel 1990; Greenbaum et al. 1996; Madaus 2006; Madaus et al. 2002). Although our graduates with dyslexia perceived that they needed to work harder and longer than their peers to be successful, that perception did not appear to negatively affect the amount of stress they experienced at work. Perhaps the ability to adapt to a college-level work load and acceptance of their dyslexia helped to mitigate against the stress of requiring more time to complete tasks, especially if the graduates with dyslexia were employed at jobs that enabled them to use their strengths. Qualitative responses from graduates with dyslexia highlighted strengths in the areas of perseverance and selfperceived creativity and unconventional thinking. One participant wrote, "I find I look at the bigger picture and can solve problems" and another wrote, "I think I take a more creative approach to problems or at least approach problems in a different way." Similarly, another respondent remarked, "There's definitely a trade-off here but at this point in my life, I'm really thankful for the advantages that the different way of thinking my dyslexia provides me." These responses are consistent with our finding that graduates with dyslexia reported greater self-perceived creativity than typical graduates. Although there is no consensus about how to define and measure creativity, some research studies have found enhanced creative talents within dyslexic populations and suggest that dyslexia may lead to enhanced practice in out-of-the-box thinking, perhaps, to overcome some of the problems associated with the disability (Everatt et al. 1999; Tafti et al. 2009).

\section{Conclusions}

Our findings indicate that for the most part, in college and in the workplace, both DR and TR groups experienced positive outcomes. Successfully negotiating school enabling them to consider and apply to and be accepted at a selective college followed by 4 years of college may have enabled dyslexic students to develop effective coping strategies and to accept, and ultimately reframe, their dyslexia. Finding so few significant differences between dyslexic and non-dyslexic Yale alums led us to conclude that when intellectually able and motivated students with dyslexia are given academic opportunity at a rigorous institution they can succeed academically, professionally, and personally.

These findings offer an unexpected yet reassuring picture of the college and career success of individuals with dyslexia. Our graduates with dyslexia appeared to compensate for their disability by accessing their strengths. Parents of dyslexic children often ask about their child's future. These findings should reassure those professionals (including pediatric neuropsychologists, school psychologists and pediatricians) that dyslexic students can succeed all along the developmental pathway from school entry, throughout school and now through college and the workplace. Details of how dyslexic students should optimally prepare for college, the application to college, and how best to navigate the college experience are discussed by us elsewhere. (Shaywitz and Shaywitz 2020).

Many of our graduates with dyslexia had originally referred themselves to the Yale Center for Dyslexia and Creativity with concerns about their learning that were unaddressed or only partially addressed during their secondary 
schooling, even if they had a definite diagnosis of dyslexia. Educators at the high school level need to increase their understanding and knowledge of dyslexia so they can, in turn, provide their students with more accurate and up-to-date information about dyslexia and the interventions and accommodations that will be most helpful (Janiga and Costenbader 2002; Skinner and Lindstrom 2003).

Our findings suggest that when bright, motivated students with dyslexia are given the opportunity to attend a rigorous, selective college, they are able to fare as well as their peers during college and following graduation. Earlier studies now approaching or more than two decades old found that students with learning disability typically applied to college with lower SAT and/or ACT scores than their peers (Reiff et al. 2001; Vogel and Adelman 1990, 1992). Neither of these studies reported whether the students received testing accommodations such as extra time on these tests. Furthermore, there are now over 1000 colleges that do not require SAT/ACT scores as part of the admission process. Our findings indicate that especially for applicants with dyslexia, college admission officers must consider more than simply SAT/ACT scores, but intrinsic qualities such as self-awareness, motivation, and selfadvocacy in selecting their class. Thus, it is vital for college admission officers and college guidance counselors to consider an array of factors when evaluating prospective college students with dyslexia.

\section{Limitations}

Limitations of the current study include the relatively small sample, and the population drawn from a highly selective college suggest some caution in generalizing our results to graduates of other institutions. In addition, our sample with dyslexia comprised only those individuals who sought and received academic accommodations during college enrollment and could be different from those students who did not request academic accommodations.

Acknowledgements We thank Linda Lorimer, former VP of Yale, who did so much to help bring about positive steps forward for Yale dyslexic students.

Funding This work was supported by the Yale Center for Dyslexia and Creativity and the Seedlings Foundation.

\section{Compliance with Ethical Standards}

Conflict of Interest None of the authors have any potential conflicts of interest to disclose.

Open Access This article is licensed under a Creative Commons Attribution 4.0 International License, which permits use, sharing, adaptation, distribution and reproduction in any medium or format, as long as you give appropriate credit to the original author(s) and the source, provide a link to the Creative Commons licence, and indicate if changes were made. The images or other third party material in this article are included in the article's Creative Commons licence, unless indicated otherwise in a credit line to the material. If material is not included in the article's Creative Commons licence and your intended use is not permitted by statutory regulation or exceeds the permitted use, you will need to obtain permission directly from the copyright holder. To view a copy of this licence, visit http://creativecommons.org/licenses/by/4.0/.

\section{References}

Adelman, P. B., \& Vogel, S. A. (1990). College graduates with learning disabilities: employment attainment and career patterns. Learning Disability Quarterly, 13(3), 154-166. https://doi.org/10.2307/ 1510698.

Cosden, M. A., \& McNamara, J. (1997). Self-concept and perceived social support among college students with and without learning disabilities. Learning Disability Quarterly, 20(1), 2-12.

Everatt, J., Steffert, B., \& Smythe, I. (1999). An eye for the unusual: creative thinking in dyslexics. Dyslexia: the Journal of the British Dyslexia Association, 5(1), 28-46. https://doi.org/10.1002/(SICI) 1099-0909(199903)5:1<28::AID-DYS126>3.0.CO;2-K.

Ferrer, E., Shaywitz, B., Holahan, J., Marchione, K., \& Shaywitz, S. (2010). Uncoupling of reading and IQ over time: empirical evidence for a definition of dyslexia. Psychological Science, 21(1), 93-101.

Ferrer, E., Shaywitz, B., Holahan, J., Marchione, K., Michaels, R., \& Shaywitz, B. (2015). Achievement gap in reading is present as early as first grade and persists through adolescence. Journal of Pediatrics, 167(5), 1121-1125.

First Step Act (2018). Pub. L. No. 115-391 (Office of the Federal Register through the Congressional Printing Management Division, U.S. Government Printing Office 2018).

Gerber, P. J., Reiff, H. B., \& Ginsberg, R. (1996). Reframing the learning disabilities experience. Journal of Learning Disabilities, 29(1), 98101.

Greenbaum, B., Graham, S., \& Scales, W. (1996). Adults with learning disabilities: occupational and social status after college. Journal of Learning Disabilities, 29(2), 171-173.

Herrera-Araujo, D., Shaywitz, B. A., Holahan, J. M., Marchione, K. E., Michaels, R., Shaywitz, S. E., \& J.K., H. (2017). Evaluating willingness to pay as a measure of the impact of dyslexia in adults. Journal of Benefit Cost Analysis, 8(1), 24-48. https://doi.org/10. 1017/bca.2017.3.

Janiga, S. J., \& Costenbader, V. (2002). The transition from high school to postsecondary education for students with learning disabilities: a survey of college service coordinators. Journal of Learning Disabilities, 35(5), 463-470.

Lewandowski, L., \& Arcangelo, K. (1994). The social adjustment and self-concept of adults with learning disabilities. Journal of Learning Disabilities, 27(9), 598-605.

Madaus, J. W. (2006). Employment outcomes of university graduates with learning disabilities. Learning Disability Quarterly, 29(1), 19-31.

Madaus, J. W., Foley, T. E., McGuire, J. M., \& Ruban, L. M. (2002). Employment self-disclosure of postsecondary graduates with learning disabilities: rates and rationales. Journal of Learning Disabilities, 35(4), 364-369. https://doi.org/10.1177/ 00222194020350040701.

Madaus, J. W., Ruban, L. M., Foley, T. E., \& McGuire, J. M. (2003). Attributes contributing to the employment satisfaction of university graduates with learning disabilities. Learning Disability Quarterly, 26(3), 159-170. https://doi.org/10.2307/1593649. 
Madaus, J. W., Zhao, J., \& Ruban, L. (2008). Employment satisfaction of university graduates with learning disabilities. Remedial and Special Education, 29(6), 323-332. https://doi.org/10.1177/ 0741932507312012.

Morgan, W. P. (1896). A case of congenital word blindness. British Medical Journal, 1378.

Reiff, H. B., Hatzes, N. M., Bramel, M. H., \& Gibbon, T. (2001). The relation of LD and gender with emotional intelligence in college students. Journal of Learning Disabilities, 34(1), 66-78.

Shaywitz, S., \& Shaywitz, J. (2020). Overcoming dyslexia (2nd ed.). New York: Alfred A. Knopf.

Skinner, M. E., \& Lindstrom, B. D. (2003). Bridging the gap between high school and college: Strategies for the successful transition of students with learning disabilities. Preventing School Failure: Alternative Education for Children and Youth, 47(3), 132-137.
Tafti, M. A., Hameedy, M. A., \& Baghal, N. M. (2009). Dyslexia, a deficit or a difference: comparing the creativity and memory skills of dyslexic and nondyslexic students in Iran. Social Behavior and Personality: An International Journal, 37(8), 1009-1016.

Vogel, S. A., \& Adelman, P. B. (1990). Extrinsic and intrinsic factors in graduation and academic failure among LD college students. Annals of Dyslexia, 40(1), 117-137.

Vogel, S. A., \& Adelman, P. B. (1992). The success of college students with learning disabilities: Factors related to educational attainment. Journal of Learning Disabilities, 25(7), 430-441.

Publisher's Note Springer Nature remains neutral with regard to jurisdictional claims in published maps and institutional affiliations. 